\title{
XXXII. On magnetization in strong fields at different temperatures
}

\author{
H. E. J. G. du Bois
}

To cite this article: H. E. J. G. du Bois (1890) XXXII. On magnetization in strong fields at different temperatures, Philosophical Magazine Series 5, 29:179, 293-306, DOI: $10.1080 / 14786449008619943$

To link to this article: http://dx.doi.org/10.1080/14786449008619943

曲 Published online: 08 May 2009.

Submit your article to this journal $\lceil\pi$

Џ Article views: 1

Q View related articles $\asymp$ 
IONDON, EDINBURGH, AND DUBLIN

\title{
PHILOSOPHICAL MAGAZINE
}

\author{
AND \\ JOURNAL OF SCIENCE.
}

[FIFTH SERIES.]

$A P R I L \quad 1890$.

XXXII. On Magnetization in Strong Fields at Different Temperatures. . By H. E. J. G. DU BoIs, of the Hague*.

[Plate VIII.]

§1. INTRODUCTORY.-Prof. Rowland, in summarizing his well-known magnetic researches (1873), thus carefully expresses himself :-

" (7) Iron, nickel, and cobalt all probably have a maximum of magnetization, though its existence can never be entirely established by experiment, and must always be a matter of inference; but if one exists, the values must be nearly as follows at ordinary temperatures. Iron when $\mathfrak{B}=17500$ or when $\mathfrak{I}=1390$; nickel when $\mathfrak{B}=6340$ or when $\mathfrak{I}=494$; cobalt when $\mathfrak{B}=10000($ ?) or when $\mathfrak{S}=800($ ?)" $\dagger$. Until lately, nothing decisive was done in the matter, apart from occasional announcements of $\mathfrak{I}$ having been found $>1390$ for iron; and Rowland's values had to be adopted by experimenters, including myself (Phil. Mag. Nov, 1887) ‡. Mr. Shelford Bidwell's experiments on the lifting-power of divided ring-electromagnets (up to $\mathfrak{5}=585$ ) furnish important

* Paper read before the Physical Society of Glasgow University, Nov.8, 1889 ; a synopsis of results had been communicated to the Brit. Assoc,, Newcastle (see Proceed. Sect. A, Sept. 17, 1889 Report).

I Rowland, Phil. Mag. [4] xlviii. p. 339 (1874); reduced to C.G.S. units.

$\ddagger$ Compare Fromme's comments, Wied. Ann. xxxiii. p. 234 (1888)

Phil. Mag. S. 5. Vol. 29. No. 179. April 1890. 2 A 
evidence for the continual increase of the Induction, proportional to the square root of the weight supported. However, I cannot quite agree with the author's way of calculating the curve of magnetization*. Quite recently Messrs. Ewing and Low $\dagger$ published the final results obtained with their ingenious "isthmus" method, which disprove the existence of a limit to $\mathfrak{B}$, the induction having been forced up to over 45,000 C.G.S. The authors further conclude that the magnetization remains sensibly constant throughout the extensive range of magnetizing field (2000 to 20,000 C.G.S.) which they were the first to apply.

\$2. Mainly with a view to check these results by an altogether different method, and to obtain more accurate data than the isthmus method, as developed at present, appears capable of supplying, I undertook the experiments to be described. Excepting Mr. Bidwell's 585 C.G.S., fields over a fow hundred units hardly appear to have been applied in coils; I therefore began with a powerful coil giving up to 1300 C.G.S. Thence upward to 13,000 an optical method, based on Kerr's phenomenon $\ddagger$, was used. I have also studied the effect of temperature with these strong fields; considerable interest having been lately attached by various authors to theoretical thermomagnetic speculations; and thermomagnetic motors having been proposed by Thomson-Houston, Schwedoff, Stefan, Edison, and others $\$$. In conclusion, the important part played by magnetization in affecting the properties of matter is discussed.

Throughout this paper I shall as usual denote by: $\mathfrak{S}$, magnetic intensity; $\mathfrak{B}$, induction ; when the values of these quantities inside the metal are considered, they are denoted by $\mathfrak{S}^{\prime}$ and $\mathfrak{B}^{\prime} ; \Im$, magnetization; $D$, density ; $\mathfrak{S}=\Im / D$, specific

* The magnetic intensity $\mathfrak{S}$ in the thin air-films between the halves of the ring evidently equals $\mathfrak{B}^{\prime}$, the induction in the iron. Now the tractive force per unit section is equal to the tension in the lines of force

$$
\mathrm{G}=\mathfrak{S}^{2} / 8 \pi=\mathfrak{B}^{\prime 2} / 8 \pi=2 \pi \mathfrak{S}^{2}+\mathfrak{S S}^{\prime}+\mathfrak{S}^{\prime 2} / 8 \pi ;\left[\therefore \mathfrak{B}^{\prime}=\mathfrak{S}^{\prime}+4 \pi \mathfrak{I}\right]
$$

(for notation, see $\$ 2$ ). This adaptation of Maxwell's formula by Rowland, Mr. Bidwell (Proc. Roy. Soc. xl. p. 492, 1886) finds "clearly erroneous," though I fail to see why. He adopts the formula

$$
\mathrm{G}=2 \pi \mathfrak{S}^{2}+\mathfrak{S} \mathfrak{h}^{\prime} \text {; }
$$

the missing term $\mathfrak{S}^{\prime 2} / 8 \pi$ appears, from the action-at-a-distance point of view, to correspond to the mutual electrodynamic attraction of the two half-coils, neglected by Mr. Bidwell.

† Ewing and Low, Phil. Trans. clxxx. p. 221 (1889).

f See du Bois, Wied. Ann. xxxix. p. 25 (1890); transl., Phil. Mag. ante, p. 253, the paragraphs of which will be referred to as loc. cit.

\$ See Stefan, Wien. Berichte, xcvii. 2, p. 70 (1888). Kittler, Handbuch der Elektrotechnik, ii. p. 47 (1890). 
magnetization, i.e. moment per unit mass ; $\theta$, temperature ; $\epsilon_{0}$, rotation of plane of polarization ; K, "Kerr's constant." C.G.S. units are tacitly assumed, wherever the contrary is not expressly stated; compare loc. cit. $\$ 5$.

\section{Magnetometric Observations.}

§ 3. Apparatus.-Four elongated ovoids (prolate ellipsoids of revolution) of length 18 centim. and diameter 6 centim. (ratio 1/30) were prepared and could be uniformly magnetized in the coil. On account of their non-endlessness a correction of ${ }^{\circ} 052 \mathfrak{I}^{*}$ bad to be subtracted from the field $\mathfrak{j}$ of the coil in order to obtain the real magnetic intensity $\mathfrak{S g}^{\prime}$ inside the ovoid. The following metals were tested :-

(a) Soft Swedish iron, carefully annealed: $\mathrm{D}=7 \cdot 82$.

(b) Hard English cast steel, yellow-tempered at $230^{\circ}$ : $\mathrm{D}=7 \cdot 78$.

(c) Hard-drawn best nickel wire : $\mathrm{D}=8.82$ (from the "Nickelwalzwerk" in Schwerte, Westphalia); stated by the makers to contain 99 per cent. $\mathrm{Ni}$, besides $\mathrm{SiO}_{2}$ and traces of $\mathrm{Fe}$ and $\mathrm{Cu}$.

(d) Cast cobalt : D about 8.0 (from Messrs. Johnson and Matthey). My friend Dr. Serda kindly analysed this for me with the following result:-Co $93 \cdot 1$ per cent., Ni 5.8 per cent., $\mathrm{Fe} \cdot 8$ per cent., $\mathrm{Cu} \cdot 2$ per cent., $\mathrm{Si} \cdot 1$ per cent., $\mathrm{C} \cdot 3$ per cent. Rather unsatisfactory brittle material; the ovoid broke in the lathe; it was thought best to scrape the fractured ends truly plane, and to hold them tightly pressed together in a brass tubular screw-and-nut arrangement $\uparrow$.

The coil was wound to the following dimensions: length 30 centim.; inner diameter 4 centim.; outer diameter 12 centim.; 12 layers, each of 90 turns, of double cotton-covered shellacked wire, $\cdot 25$ centim. in diameter ; resistance cold $\cdot 9$ ohm. It could be surrounded by an ice-jacket; with a dynamo-current of $32 \mathrm{amp}$. almost a kilo-watt of activity was being dissipated in it, sufficient to melt a $\mathrm{kg}$. of ice every five minutes. In other cases the coil was electrically heated.

$\S 4$. The ovoids, fixed inside the coil, could be maintained at $0^{\circ}$ or $100^{\circ}$ by ice or steam properly applied. The arrangement for heating them over $100^{\circ}$ and the mode of determining the field are described, loc. cit. $\$ \$ 4$ and 14 . The whole of this apparatus was placed in Gauss's "first position," about 135 centim. due east of a magnetometer. It was

* See Maxwell, Treatise, 2nd ed. ii. § 438, form. (14).

$\dagger$ See J. J. Thomson and Newall, Proc. Cambr. Phil. Soc. vi. p. 84 (1887); Ewing and Low, Phil. Mag. [5] xxvi. p. 275 (1888). 
attempted to compensate the very considerable action of the coil alone by that of another similar one, placed due west and in the same circuit. Great difficulty was experienced with this, principally due to heating of the coils and parasitic action of distant current leads. Finally the idea of total compensation had to be given up, and the remaining difference was each time carefully determined and corrected for. The earth's horizontal intensity at the magnetometer's site was measured once for all ; its fluctuations being followed with one of Prof. F. Kohlrausch's local variometers. Thus the magnetic moments of the ovoids could be accurately obtained in absolute measure.

§ 5. Preliminary trials.-I began by trying whether there was a perceptible influence of magnetic history in general; or of the hysteresis, due to its latest phases, in particular. The ovoids were therefore made to pass through various magnetic ordeals, as descending or ascending currents, reversals, \&c. None were found, however, to have an appreciable effect, except with fields below 150 C.G.S., say, where such an influence occurred, though slightly. 'The reasons for this are no doubt:(1) the ovoids had too little of endlessness to exhibit much hysteresis in any case ; (2) the slightly pulsating machinecurrent effectually counteracts it by its shaking action; and (3) probably hysteresis really comes less to the foreground with such strong magnetizing fields.

However this may be, I was thereby free to magnetize in whatever manner I chose; as a rule, two magnetometerreadings were taken with currents reversed. The moment for a given temperature may thence be plotted in a loopless curve as a function of $\mathfrak{g}^{\prime}$ only, provided the latter exceed 100 C.G.S. say. Neither was I sensibly troubled with the well-known acyclic shaking-in action of temperature-variations ; perfectly consistent results being obtained with strong fields whether on heating or on cooling. Accordingly the moment due to a given magnetic intensity may be considered a function of the temperature only:

§ 6. Magnetic curves.-After much hesitation I decided not to plot $\mathfrak{\Im}$ as usual, but the specific magnetization $\mathfrak{S}$. The principal reason for this was that the results became more comparable by thus eliminating the density, which depends on temperature and other physical conditions of the material, and could moreover not be determined for the electrolytic metals tested $(\S 8)$. In fact, magnetism being an essentially molecular phenomenon, it is for certain purposes more rationally 
referred to unit mass, which always contains the same number of molecules, than to unit volume, which does not. In Pl.VIII. fig. 1 the long curves represent $\mathfrak{S}=$ funct. $\left(\mathfrak{g}^{\prime}\right)$ over a range evident from the scale of abscissæ. The origins do not occur in the diagrams, excepting that for nickel, which is joined to the first experimental point $\odot$ in a manner approximately estimated from known data. From these curves others may readily be calculated ; in particular, those representing $\mathfrak{I}=$ funct. $\left(\mathfrak{B}^{\prime}\right)$, which will be referred to below.

§ 7. Effect of temperature.-The upper curves of magnetization for iron and steel correspond to $0^{\circ}$. It will be seen that at first they almost coincide with those for $100^{\circ}$, bat that the difference increases towards larger abscissæ. For $\mathfrak{y}^{\prime}$ constant *, equal to about 900 C.G.S., $\mathcal{S}=$ funct. $(\theta)$ was then determined. It is represented by the short temperaturecurves to the left of fig. 1, plotted to the separate scale of abscissæ. They all show a decrease of $\mathfrak{S}$; the latter evidently always being above its critical value, below which it is known to increase on heating. The nickel curve falls off less abruptly than it is known to do for weaker magnetizing fields. Hence in an infinitely strong field the magnetization of all these metals would probably begin by decreasing at a quicker rate still; then to fall off without any abruptness towards practically vanishing values (see $\$ 13$ ).

On the hypothesis of magnetic molecules, this case corresponds to the temperature-variation of the individual molecular moments, because the supposed infinite field would direct the axes of all the molecules parallel to itself. It is the simplest case ; the abrupt changes and other complications observed with ordinary fields being due to the action of temperature on the direction of the molecular axes. All this was theoretically pointed out by Prof. G. Wiedemann $\dagger$. As far as I can see, my results nowhere contradict any previous thermomagnetic researches, conducted with much lower fields, though partly at higher temperatures, by G. Wiedemann, Rowland, Baur, Wassmuth, Ewing, Berson, Ledeboer, Tomlinson, J. Hopkinson, and others.

\$ 8. Additional experiments were made on material slightly differing in condition or quality from that above detined (in \$3). Annealing the hard-drawn nickel caused the

* Of course it was the current, and with it the field $\mathfrak{S}$, which was actually kept constant ; but the increase of $\mathfrak{S}^{\prime}=\mathfrak{S}-.052 \mathfrak{S}$, amounts to but 2 per cent. even when, as with nickel, $\mathfrak{I}$ falls off from 500 to 0 .

† Leh re $v$. d. Elektrizität, iii. $\$ 802$. 


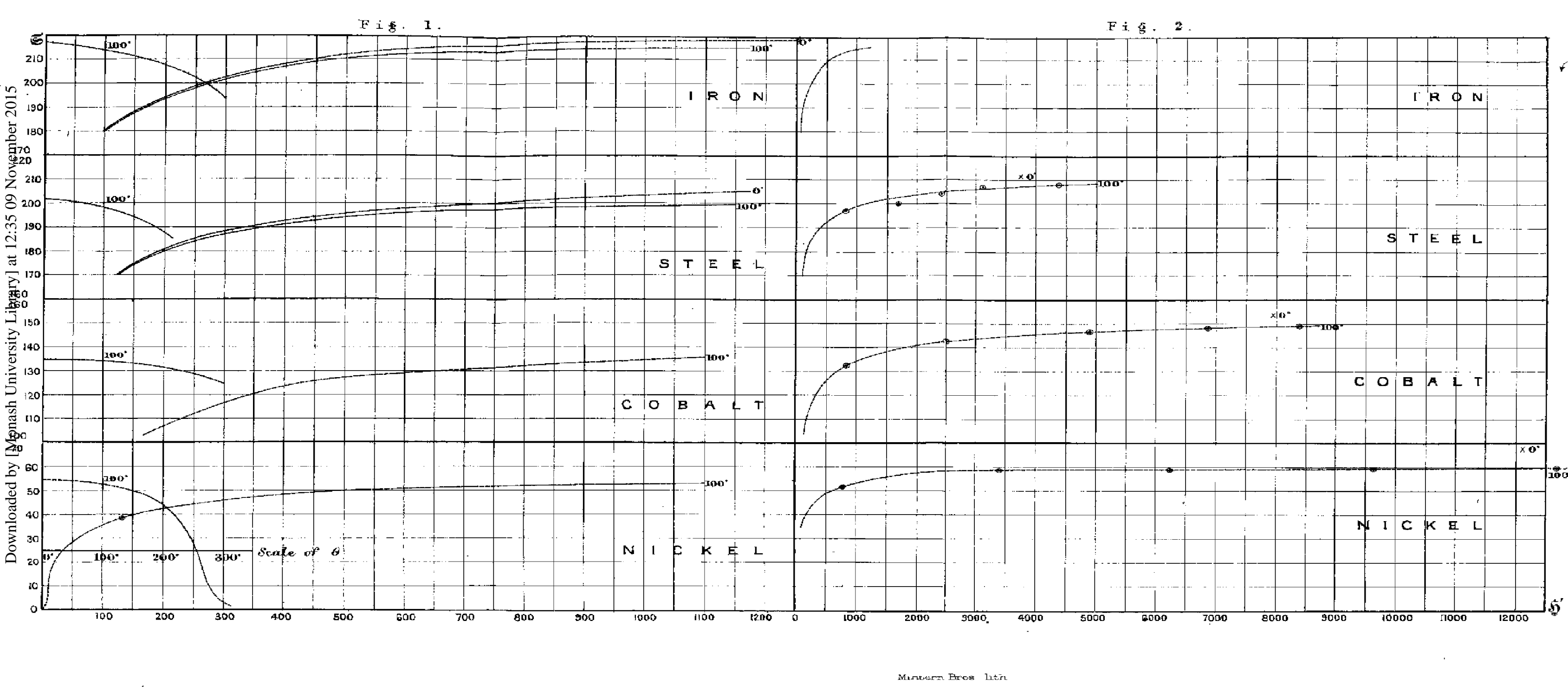

Phil. Mas S. 5 Vol 29 Pi Vy

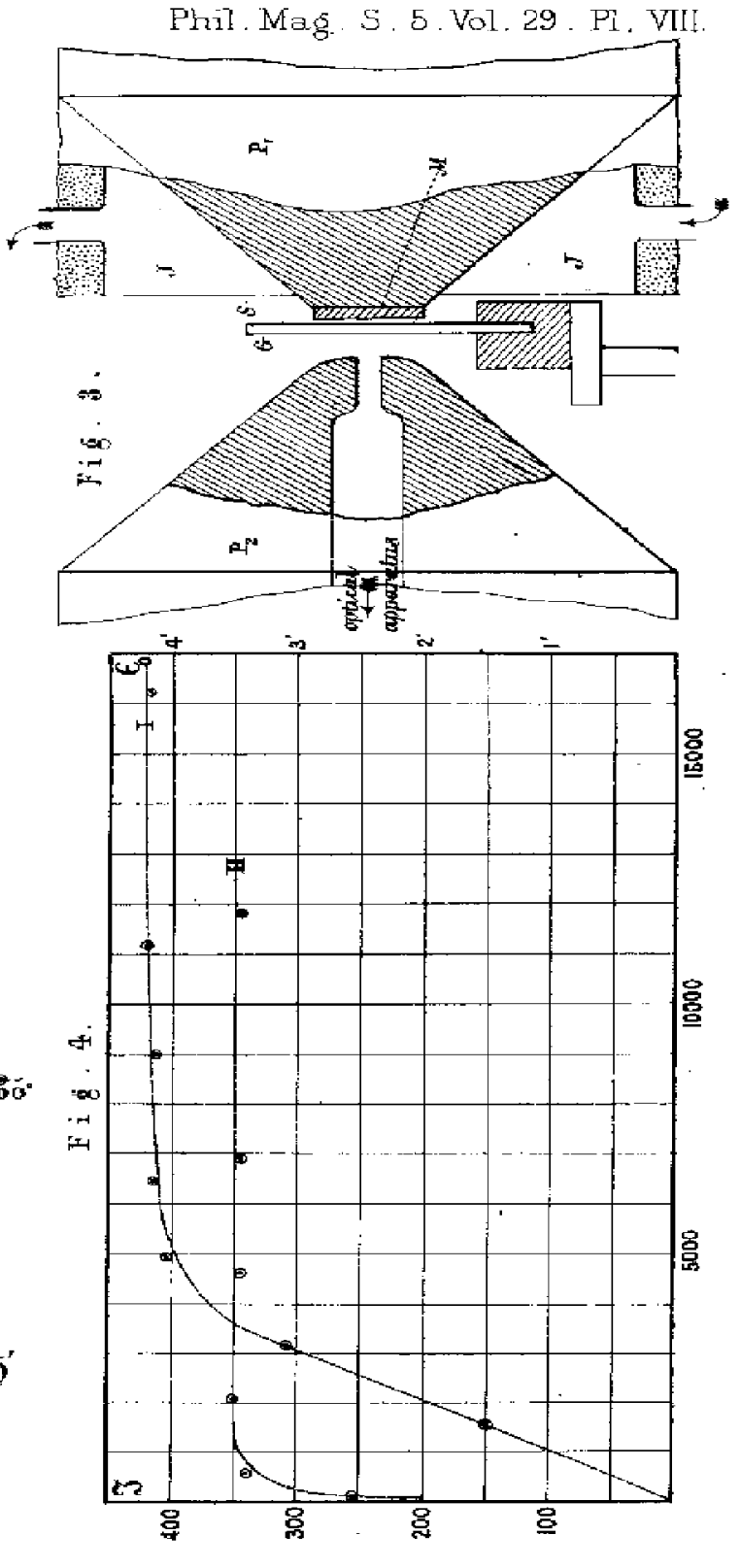


magnetic curve to rise much more rapidly at first without, however, attaining in the end to values beyond those of the nnannealed metal. The yellow-tempered hard steel was further tempered dark blue and finally annealed at red heat without any very marked change in the general character of the curve ensuing.

The values of $\mathfrak{E}$, found for iron and nickel, are 216.1 and $54^{\circ} 0$ respectively at $25^{\circ}$, as interpolated on the temperaturecurves of fig 1. Thin sheets of electrolytic iron and nickel were now prepared in the shape of oblong ellipses and weighed. They were subjected (at ordinary temperature) to a field of 900 C.G.S., and their moments approximately measured with the following results :-

a. Iron, about 05 centim. thick, originally intended for printing Russian banknotes, and kindly given to $m e$ by Prof. F. Kohlrausch : $\mathfrak{S}=211 \cdot 4,30$ per cent. of which was residual.

b. Iron, about 005 centim. thick, which I electrolytically obtained from the so-called Varrentrapp bath : $\mathfrak{S}=213.7$, 50 per cent. of which was residual.

c. Nickel, about 015 centim. thick, from citrate of nickel : $\mathfrak{S}=53.5,20$ per cent. of which was residual.

Electrolytic cobalt could not be got in films sufficiently thick for this purpose. The results appear to warrant the conclusion that with these very strong magnetizing fields much does not depend on the quality of the metal, as long as it is tolerably pure. Nor has its condition, as resulting from the mechanical and thermal treatment previously applied, any sensible influence. Of course the experiments in this paragraph are meant to be novel only with respect to the strong fields applied.

\section{Magneto-optic Observations.}

§9. Method and Apparatus.-As the isthmus method is based on the principle of tangential continuity of $\mathfrak{G}$ and discontinuity of $\mathfrak{B}\left(\mathfrak{W}^{\prime}=\mathfrak{V}\right.$ and $\left.\mathfrak{B}^{\prime}>\mathfrak{B}\right)$, so the method to be described may be said to rest on the normal discontinuity of $\mathfrak{S}$ and continuity of $\mathfrak{B}\left(\mathfrak{y}^{\prime}<\mathfrak{H}\right.$ and $\left.\mathfrak{B}^{\prime}=\mathfrak{B}\right)$. In addition, the normal component of $\mathcal{F}$ is measured by the rotation impressed upon plane-polarized light normally reflected from the magnetized metal. In order to obtain the former the latter has only to be divided by a factor, which I have proposed to call "Kerr's constant", (loc. cit. \$ 24).

The optical apparatus used for accurately measuring the rotation of red light has been described at length (loc. cit. 
$\S \S 2,16)$. Small disks $M$ were turned out of the same material as that above defined $(\S 3)$, and polished on one side. These mirrors were fixed to one pole $P_{1}$ of a Ruhmkorff electromagnet (see PI. VIII. fig. 3, full size). On its way towards the reflecting surface and back the light passed through the narrow bore of the other pole $P_{2}$, which thus screened off all but a small central patch of the mirror. Here the lines of induction evidently issue normally from the metal for reasons of symmetry. $\bar{P}_{1}$ and $M$ could be kept very nearly at $100^{\circ}$ by means of a steam-jacket JJ.

$\$ 10$. A very thin standard glass-plate $G$, silvered (S) at the back, could be placed immediately in front of the mirror. The light then being reflected in it suffers a double magnetic rotation in the glass; this affords a measure for the field $\mathfrak{I}$ directly in front of the metal, equal, by the principle of continuity alluded to, to the induction $\mathfrak{B}^{\prime}$ immediately inside it. The glass plate had previously been magneto-optically standardized by comparison with bisulphide of carbon, whose Verdet's constant is known from the determinations of Lord Rayleigh and Koepsel ; such standards are very convenient. Owing to Ruhmkorff's well-known construction the ray has to pass through one of the coils on its way to and from M through $\mathrm{P}_{2}$. The ensuing very slight donble rotation in the magnetized air must be proportional to the eurrent, and may be calculated from the data of $H$. Becquerel, Kundt and Röntgen. It was in every case corrected for, the maximum value being $+\cdot{ }^{\prime}$; I have actually observed about this rotation with a silver mirror.

\$11. Results.-The first thing experimentally obtained was the curve $\epsilon_{0}=$ funct. $\left(\mathfrak{B}^{\prime}\right)$, whose ordinates must be and were actually found proportional to those of $\mathfrak{S}=$ funct. $\left(\mathfrak{P}^{\prime}\right)$; the latter being calculated from $\mathfrak{S}=$ funct. $\left(\tilde{\mathfrak{D}}^{\prime}\right)$, as far as this goes (see $\S 6$ ). In order further to exemplify the somewhat complicated mode of calculation the numbers for cobalt and nickel are given in Table I. Here the italics are the three highest corresponding values of $\mathfrak{I}$ and $\mathfrak{B}^{\prime}$, indirectly given by the magnetometric method; the ordinary type refers to the five highest corresponding values of $\epsilon_{0}$ and ' $\mathfrak{B}$ ', obtained magneto-optically with all possible accuracy $t$. The value of $\$$ marked $*$ is interpolated from those above and below ; it corresponds to the rotation $\epsilon_{0}$ printed to its left; the ratio of

$+I$. e. from 30 observations of the analyser's azimuth; the smaller values of $\epsilon_{0}$ were based on 4 observations and measured only in order to approximately check the whole method by the proportionality of ordinates above alluded to. 
Table I.

\begin{tabular}{|c|c|c|c|c|c|c|c|}
\hline \multicolumn{4}{|c|}{ Cobalt. } & \multicolumn{4}{|c|}{ Nickel. } \\
\hline$\theta$. & $\mathfrak{B}$ '. & $\epsilon_{0}$. & $\Im$. & $\theta$. & $\mathfrak{B}^{\prime}$. & $\epsilon_{0}$ & $\mathfrak{3}$. \\
\hline $100^{\circ}$ & 14120 & $\ldots . .$. & 1058 & $100^{\circ}$ & 5980 & ...... & 487 \\
\hline 100 & 14180 & $-20 \cdot 97$ & $1060^{*}$ & 100 & 6420 & $-7 \cdot 25$ & $453^{3 *}$ \\
\hline 100 & 14410 & ....... & 1070 & 100 & 6490 & ....... & 456 \\
\hline 100 & 14650 & ...... & 1081 & 100 & 6810 & ...... & 461 \\
\hline 100 & 16750 & $-22 \cdot 45$ & $1134 t$ & 100 & 9920 & $-8 \cdot 29$ & $518 \dagger$ \\
\hline 100 & 19550 & $-23 \cdot 24$ & $1174 t$ & 100 & 12850 & $-8 \cdot 36$ & $522 t$ \\
\hline 100 & 21710 & $-23 \cdot 38$ & $1181 \dagger$ & 100 & 16250 & $-8 \cdot 43$ & $527 \dagger$ \\
\hline 100 & 23330 & $-23 \cdot 60$ & $1192 \dagger$ & 100 & 19290 & $-8 \cdot 40$ & $525 \dagger$ \\
\hline $0^{\circ}$ & 23330 & $-24^{\prime} \cdot 39$ & $1232 \times$ & $0^{\circ}$ & 19290 & $-9^{\prime} \cdot 27$ & $579 \times$ \\
\hline
\end{tabular}

both quantities gives Kerr's constant for red light, in minutes per unit magnetization, as follows :-

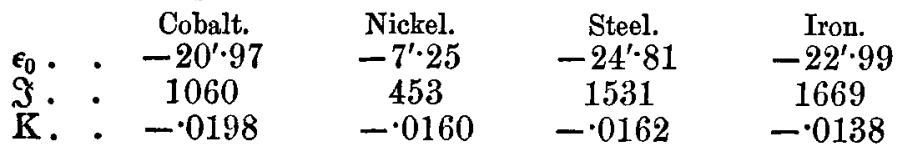

Inversely the four remaining values of $\epsilon_{0}$ were now divided by $K$, thus giving $\mathfrak{I}=$ funct. ( $\mathfrak{B}^{\prime}$ ) marked $\dagger$ in the Table. From this again $\mathfrak{S}=$ funct. $\left(\mathfrak{f}^{\prime}\right)$ conld be calculated, which thus forms a continuation of the curves obtained before (in $\$ 6$ ).

$\$ 12$. In fig. 2 the results of both methods are combined into continuous magnetic curves, now extending, at least in the case of nickel, from $\mathfrak{\mathfrak { y }}^{\prime}=150$ to $\mathfrak{S}^{\prime}=13,000$ C.G.S. The scale of abscissæ is ten times smaller than in fig. 1 , and the additional points $\odot$ are those derived from the optical method. As the strongest field $\mathfrak{S}$ of the Ruhmkorff attained about 25,000 C.G.S. it is evident that the maximum intensity $\mathfrak{S}^{\prime}$, obtainable inside the metal $\left(\mathfrak{y}^{\prime}=\mathfrak{5}-4 \pi \mathfrak{I}\right)$, is less the more strongly magnetic the metal used. Thus in fig. 2 the abscissæ extend to 8500 for cobalt, to 4500 for steel, to but 2500 for iron; the latter's curve is therefore not continued beyond $\mathfrak{5}=1200$, the point reached in fig. 1 ; the more so as the iron gave somewhat irregular results on account of the mirror's polish not being perfect. The rotational dispersion being much greater for iron and steel contributed to make the 
optical measurements with the only approximately homogeneous " red" light less accurate than for cobalt and nickel (loc. cit. $\$ 21)$; another reason for attaching most importance to these latters' curves.

$\S 13$. Nearly all optical observations were made, with steam on, at $100^{\circ}$; cooling to $0^{\circ}$ would not do on account of the dew condensing on the mirror. A few measurements were, however, made with the strongest fields at ordinary temperature; the rotations proved greater than at $100^{\circ}$ in every case, and their values for $0^{\circ}$ were obtained by simple extrapolation; they are given at the bottom of Table I. The values of $\mathfrak{I}$ marked $x$ were culculated on the assumption of absolute invariability of Kerr's constant with temperature, whereas I have only shown the variations to be less than the limit of experimental errors (a few per cent. per $100^{\circ}$, loc. cit. $\S 15)$. The corresponding values of $S$ are marked $\times 0^{\circ}$ in the diagrams of fig. 2 for steel, cobalt, and nickel. From a comparison with the short temperature-curves of fig. 1 it would appear (always on the above assumption) as if the decrease of magnetization from $0^{\circ}$ to $100^{\circ}$ were much more marked for fields of thousands of units than for lower ones. The conclusion of $\S 7$ is based on this inference.

$\S 14$. Magnetite (see loc. cit. $\S 17$ ).-Curve I. of fig. 4 represents $\epsilon_{0}=$ funct. $\left(\mathfrak{B}^{\prime}\right)$, experimentally determined for a small crystal of magnetite by purely optical observations (at ordinary temperature) ; its ordinates must be proportional to those of $\mathfrak{I}=$ funct. $\left(\mathfrak{B}^{\prime}\right)$. Now the latter function is unknown for this material, but it may be asserted to start from the origin very nearly as a straight line $\mathfrak{S}=\mathfrak{B}^{\prime} / 4 \pi^{*}$. On inspection of curve I. the two observed points $\odot$ nearest the origin are accordingly seen to lie almost in line with it. Now multiplication of these two values of $\epsilon_{0}$ into the corresponding ones of $4 \pi / 3^{\prime}$ is easily seen to give Kerr's constant as +.0122 and +.0115 for the two points respectively; the mean value $+\cdot 012$ will be sufficiently near the truth for our present purpose.

We consequently divide the ordinates of $\epsilon_{0}=$ funct. $\left(\mathfrak{B}^{\prime}\right)$ by $\cdot 012$ and thus obtain $\mathfrak{S}=$ funct. $\left(\mathfrak{V}^{\prime}\right)$ in absolute measure. Thence $\Im=$ funct. $\left(\mathfrak{H}^{\prime}\right)$ is easily calculated and plotted as curve II. (fig. 4). The magnetization evidently tends towards a limit not much above 350 C.G.S., somewhat less than that for nickel. Our magneto-optic method has thus given an absolute magnetic curve, at least approximately,

* du Bois, Wied. Ann. xxxi. p. 952 (1887); Phil. Mag. Nov. 1887. 
without any magnetic observations having been made. In fact these are quite out of question in the present case ; and accordingly no absolute data have ever been given for magnetite or loadstone that I am aware of.

\section{Conclusion.}

$\S 15$. There can be no doubt that the curves of fig. 2 , especially those for cobalt and nickel, show a tendency to a limiting value of magnetization. This of course can never actually be observed, but the values of $\Im$ can hardly exceed $1630,1200,530$ C.G.S. respectively for the steel, cobalt, and nickel used (at $100^{\circ}$ ). Though, as explained in $\$ 12$, iron unfortunately happened to give the least trustworthy results, I may infer from my observations that the value 1750 cannot be far from the truth (also at $100^{\circ}$ ). As regards the important question whether the approach is an asymptotic one, or whether $\mathfrak{J}$ reaches a maximum with finite values of $\mathfrak{H}$, thence to rediminish*, I cannot pretend to decide it any more than Messrs. Ewing and Low. The apparent slight decrease in the case of nickel (see Table I., $\Im=525$ ) is within the range of experimental error.

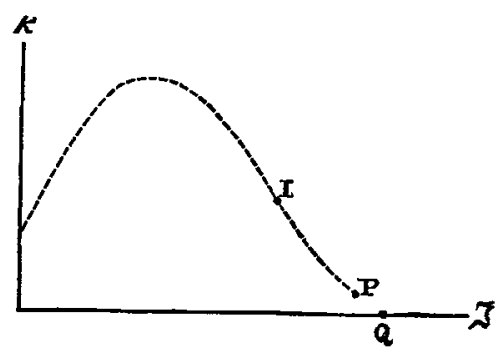

Accordingly the general type of the well-known susceptibility curves $\kappa=$ funct. ( $(\Im)$ has the point of inflexion I, as was indeed first shown for iron by Fromme and Haubner (see $\S 1$, footnote). Its continuation beyond the final experimental point $\mathrm{P}$ is a matter of inference. If there be an asymptotic limit to $\Im$, the curve will cut the axis of abscissæ in a point $Q$, and the shape of the end $P Q$ will depend on the law of approach of $\mathfrak{J}$; e.g. if the approach be like that

* See Maxwell, Treatise, ii. $\$ 844$. It may be well to observe that even in a field of 35,000 C.G.S. the magnetization of bismuth, the most diamagnetic metal known, would reach but $-\cdot 5$, i. e. $-\frac{3}{1^{0}}$ per cent. of the limiting value for nickel, so that its superposition on the latter would probably escape observation. 
of a hyperbola towards its asymptote $\mathrm{P} Q$ will be very nearly I P tangentially produced. These curves of course have nothing to do with those representing the permeability, $\mu=$ funct. $\left(\mathfrak{B}^{\prime}\right)$, which have been shown by Messrs. Ewing and Low to tend towards the asymptote $\mu=1$, for $\mathfrak{V}^{\prime}=\infty$.

$\$ 16$. The general conclusions of these physicists are entirely corroborated by the present experiments, conducted on altogether different lines. I believe all doubts, that have occasionally arisen as to the existence of a limit of Magnetization, will thereby be dissipated. In fact this quantity appears about to regain its physical importance, which has lately been perhaps too much transferred to Induction. This I will now endeavour to show, without thereby in the least wishing to contest the great advantages of induction in the mathematical theory, as well as in the practical applications of electromagnetism.

In 1842 the late James Prescott Joule * enunciated the law that the elongation of unstrained iron is proportional to the square of the magnetization applied. The same has recently been shown by M. Goldhammer to hold for the decrease of electric conductivity $\dagger$; and it can hardly be doubted that thermal conductivity varies in the same manner.

I have shown the optical rotation to be entirely dependent on and directly proportional to the magnetization on reflexion as well as on transmission (loc. cit. $\$ 23$, and Phil. Mag. Nov. 1887). Hall's effect probably follows the latter law $\ddagger$, and it is natural to suppose that the three analogous phenomena discovered by Messrs. v. Ettingshausen and Nernst will prove no exceptions.

$\S 17$. I therefore entirely agree with $M$. Goldhammer, where he points out the probability of this general law :-

"Magnetization affects all physical properties of metals in a way generally depending on its direction. Whenever the ensuing changes are odd functions of the magnetization (both simultaneously reversing their sign), they are simply proportional to it. In the case of even functions (always having the same sign), they are proportional to its square."

This statement is an expansion of ideas put forth by Sir

* Joule, Reprint of Papers, i. p. 245.

† Goldhammer, Wied. Ann, xxxvi. p. 823 (1889); Procès-verbaux, Paris Electr. Congress, Aug. 30, 1889.

¥ This statement, well worth safely establishing by experiment, is based on the following evidence: -1 . By Hall, curve for Ni, Phil. Mag. [5] xii. p. 166 (1881); 2. Residual effect in steel, Phil. Mag. [5] xix. p. 419 (1885) ; 3. Behaviour of conducting strips of various thicknesses, Sillim. Journ. [3] xxxvi. p. I8I (1888); 4. By v. Ettingshausen and Nernst, table for Co and Ni, Wien. Ber. xciv. 2. pp. 585, 587 (1886). 
W. Thomson in $1855 *$. The relation assumed to exist between the optical phenomena and Hall's effect (as extended to displacement currents) by Messrs. Rowland, H. A. Lorentz, and van Loghem $†$ appears in a certain sense as one of its particular cases. In conclusion, it may be remarked that the above phenomena are not actions at a distance, but actually occur on the selfsame spot as the magnetization, which thus appears to be their common cause, and to have a real physical existence.

\section{APPENDIX.}

\section{On Manganese Steel.}

The optical method having proved a valuable aid in the case of magnetite, it occurred to me to apply it for scrutinizing the behaviour of manganese steel. A piece of bar and some wire was kindly supplied to me by Mr. Hadfield, of the Hecla Works, Sheffield. Chemical analysis, for which I am again indebted to Dr. Serda, gave $87 \cdot 1$ per cent. Fe, 11.8 per cent. $\mathrm{Mn}, \cdot 3$ per cent. $\mathrm{Si}$, and some C. It is susceptible of an excellent polish, rather better than that on ordinary steel. However, I find it somewhat more liable to rust; after some months the polished surface showed small specks of oxide under the microscope. Rough magnetometric measurement, with the strong fields of the coil, gave an apparently constant susceptibility of only 001 , or permeability $1.013 \ddagger$; about 25 per cent. of the magnetization being residual.

On magneto-optic examination, in the manner above developed, negative rotation was found in every case. But its numerical value varied considerably according as different patches of the same polished surface were made to reflect, or as different mirrors, ground on to the same piece, were tried. The rotation on a given patch was not proportional to the

* Sir W. Thomson, Reprint of Papers, ii. p. 178.

$\uparrow$ See Wied. Beiblätter, viii. p. 869 (1884).

$\ddagger$ Literature on p. 34 of Mr. Hadfield's paper read before the Iron and Steel Institute, Edinburgh, 1888; further, Barrett, Proc. Roy. Soc. Jubl. vi. p. 107 (1888). Results of experiments made at the German marine observatory of Wilhelmshaven are given in Ann. $d$. Hydrogr. xvii. p. 177 (1889), though not in absolute measure; however, on considering the data given, the susceptibility may be estimated at .005 for the thin bar, and 0015 for the thick bar used. Ewing and Low, loc. cit., find the permeability much larger, viz. $1 \cdot 4$, and constant for magnetizing fields between 2000 and 10,000 C.G.S. This seems to show that the magnetic properties of manganese steel are exceedingly variable from one sample to another. [The same conclusion is arrived at by Dr. Paul Meyer, in an article published quite recently (Elektrotechnische Zeitschrift, $\mathbf{x}$. p. 582 (1889) after the reading of the present paper.] 
field of the Ruhmkorff, as the constant permeability at first led me to expect, but tended towards a limit. The largest rotation obtained was about $\frac{1}{3}$ of the maximum for iron. All this appears to me to show the material to be essentially heterogeneous, relatively strongly magnetic layers being interposed between the feebly magnetic mass. Probably the structure on the whole is laminar, and so fine-grained that to ordinary chemical mass-tests it appears perfectly homogeneous. The ultimate heterogeneousness is only revealed by the magneto-optical method, in which the action is restricted to a surface patch a few millim. in diameter and a fraction of a wave-length in thickness. Microseopical examination of a mirror showed a faint indication of streaks in the polished surface, and the specks of rust alluded to appeared to be arranged in definite configurations. The crystallographic method of corrosive etching was now resorted to: a drop of dilute nitric acid produced a peculiar network of microscopical surface figures, not revealed by a common steel mirror after the same treatment. This affords another proof for the heterogeneousness of manganese steel, which thus appears to be rather an unsatisfactory alloy for the physicist to deal with *, however interesting it may be to the engineer.

I believe great care should be taken in drawing conclasions from the greater or less attraction of manganese steel filings by strong magnets, this attraction proving an altogether false criterion. I have not been able to file my samples; but small particles scratched off with a glass-cutting diamond were readily attracted by any magnet. A piece of wire was then drawn out to $\frac{1}{3}$ millim. diameter, and a number of small bits, about 1 millim. long, cut off.' These also behaved like a heap of filings, and were attracted by a magnet as long as separate. But on kneading them together with very little wax, the lump was as unaffected by the magnet as a larger piece of wire or bar.

I think all this is only due to the diminutive dimensions of the particles, and to nothing else, because they may thus come very near the edges of the steel magnet. Here the space-variation of $\mathfrak{g}^{2}$, on which the attraction depends, probably is considerable. In connexion with this it may be remembered that mineralogists extract ferruginous minerals,

* In fact the ordinary theory of magnetic induction ceases to be applicable to heterogeneous solids; all results obtained by the magnetometer, isthmus, Quincke's, or any other method must therefore be regarded as untrustworthy. If, for example, the laminæ are, on the whole, perpendicular to the field, the constant permeability, found by Messis. Ewing and Low, comes out quite naturally. 


\section{Messrs. Haldane and Pembrey on an Improved Method}

though quite unmagnetic in large lumps, out of the crushed rocks with magnets. Magnetic ore-separators are also said to be used on a practical seale.

In conclusion I may mention that M. Heusler, of the Isabellenhütte, Dillenburg, kindly sent me an alloy which he defined as follows:-93-93.5 per cent. $M n, 1-1 \cdot 2$ per cent. $\mathrm{Fe}, \cdot 2-\cdot 5$ per cent. $\mathrm{Si}$, and earbon. This gave not the slightest trace of an attraction by the pole of a steel magnet or of the Ruhmkorff, whether in a piece or pounded almost to dust.

I beg to tender my best thanks to Prof. F. Kohlrausch, in whose laboratory these experiments were carried out.

Phys. Inst. of Strasburg Univ., Nov. 1, 1889.

XXXIII. An Improved Method of Determining Moisture and Carbonic Acid in Air. By J. S. Haldane, M.A., M.D., and M. S. Pembrex, B.A., Fell Exhibitioner of Christ Church, Oxford. (From the Physiological Laboratory, Oxford.) *

$\mathbf{W}^{\mathrm{E}}$ were originally led to undertake the present investigation by difficulties experienced in measuring the respiratory exchange of oxygen and carbonic acid in animals. In the method which we wished to employ the results depend on an accurate determination of the difference in the percentage of moisture and carbonic acid in the air entering and that leaving a ventilated chamber in which the animal is placed. As the ventilation current is large, the difference to be measured is a small one, and errors of analysis are correspondingly important, especially in short experiments.

Although the object of our work was thus originally physiological, we have been guided ehiefly by regard to the wider applications, particularly in meteorology, of the methods in question.

\section{The Determination of Moisture.}

Of the various methods in use for determining moisture in air the " chemical" method is generally acknowledged to be the most accurate when properly carried out. This method consists in the aspiration of a known volume of the air through one or more weighed tubes filled with a substance which absorbs moisture, such as anhydrous phosphoric acid or pumice soaked in sulphuric acid. The increase in weight of the absorption-tubes gives the weight of moisture contained in the air. The great disadvantage of this method as used

* Communicated by Prof. Odling, F.R.S. 